\title{
Consent to psychiatric treatment: practical implications of the Mental Health (Amendment) Bill
}

\author{
MARGARET A BEEDIE, ROBERT BLUGLASS
}

\begin{abstract}
The case notes of all patients admitted in 1981 to two Birmingham psychiatric hospitals on compulsory orders for treatment were examined to determine whether, had the new "consent to treatment" proposals in the Mental Health (Amendment) Bill been in operation, a second opinion was necessary. This concluded that there will be difficulties in operating the arrangements to provide a second opinion, and the Government should reconsider the range of these proposals.
\end{abstract}

\section{Introduction}

Since the introduction of the Mental Health Act 1959, psychiatrists have assumed that the compulsory detention of a psychiatric patient for treatment (sections 26,60 and 65,72 , and 73 of the Act) provides authority to treat the patient even if he is unwilling or unable to give his consent as a result of his mental disorder. Good practice requires the doctor to endeavour always to obtain the patient's informed consent if he is competent to give it. The management of the patient's case is helped by his co-operation and understanding. Most patients, however, are admitted under compulsory powers precisely because they are seriously mentally disordered. Commonly they exhibit severe psychotic states accompanied by disturbances of thought, mood, or insight, which may profoundly distort judgment and

\footnotetext{
Midland Centre for Forensic Psychiatry, All Saints' Hospital, Birmingham B18 5SD

MARGARET A BEEDIE, MRCP, MRCPSYCH, senior registrar in forensic psychiatry

ROBERT BLUGLASS, MD, FRCPSYCH, professor of forensic psychiatry
}

the ability to make a rational decision with respect to informed consent. Some are able to understand the purpose and nature of a proposed treatment but are influenced by irrational fears, persecutory delusions, or hallucinatory experiences resulting in an irrational and insightless refusal. It is usually abnormal and often self-destructive behaviour associated with such conditions that has resulted in compulsory admission and, subsequently, justifies treatment in the patient's own interests, despite his refusal or inability to give consent.

Psychiatrists have believed that the compulsory order to detain the patient incorporates the authority to give treatment. In cases of doubt, or where an unusual treatment is contemplated, good practice will dictate the need to obtain a second opinion from a colleague.

The need to improve the safeguards for detained patients and to protect their rights has resulted in a lengthy debate during the past seven years or more in an attempt to determine appropriate procedures in connection with consent to treatment. The present Government has published a Mental Health (Amendment) Bill, ${ }^{1}$ now before the House of Commons, which puts forward specific proposals to clarify the position of the patient and the doctor when treatment is to be given to a detained patient.

\section{Consent to treatment: proposals}

Clause 41 of the Mental Health (Amendment) Bill proposes amendments to the Mental Health Act $1959^{2}$ which confirm that the consent of the patient is not required except in certain specific circumstances or for particular categories of treatment.

The Bill refers to three groups of treatments.

(1) Surgical treatment, including any diagnostic procedure involving physical interference.

(2) Administration of medicine by any means.

(3) Electric convulsion therapy. 
The responsible medical officer may give any of these treatments (or procedures) to a patient detained in hospital for treatment if he (or an independent medical practitioner) has certified in writing that the patient is capable of understanding the nature, purpose, and likely effects of the proposed treatment and has consented to it.

If the responsible medical officer proposes to give any of the three categories of treatment to a patient who is not capable of understanding, or who has not given consent, then a second opinion must be obtained from an independent doctor (who will be appointed by the new Mental Health Act Commission). The independent doctor must confirm, in writing, the patient's inability to give consent, or his refusal, but that "having regard to the likelihood of its alleviating or preventing a deterioration of the patient's condition" the treatment should be given.

The Bill proposes exceptions to these rules. The doctor will be able to act without the patient's consent in an emergency and in some other limited circumstances (subsection (6) of clause 41). For treatments of special concern (irreversible or hazardous), to be specified in regulations made by the Secretary of State on the advice of the Mental Health Act Commission (or laid down in a code of practice), the patient's informed consent and a second opinion will be mandatory. For these cases the Government intends to provide that the second opinion to confirm the patient's competency to give consent will be given by a group of three members of the commission (one of them a psychiatrist). The psychiatrist will then confirm that the proposed treatment should be given.

The procedures requiring an independent medical second opinion will apply when it is proposed to treat a patient detained under one of the treatment sections of the Act, or if a diagnostic procedure is to be carried out. The Bill makes it clear that this includes section 25 (to be "admission for assessment followed by medical treatment") and a new "remand to hospital for treatment" section to be made available for mentally abnormal offenders, in addition to patients detained under sections 26 , 60 and 65,72 , and 73 . The procedures will not apply to patients admitted under the short-term sections where treatment can be given only in an emergency-sections 29, 30(2) and (3), 135 , and 136 or under a new section allowing a remand to hospital for a report to be prepared.

The Government's proposals on consent to psychiatric treatment have been debated in the House of Lords, where they were amended, and they are about to be discussed by the House of Commons. Psychiatrists have welcomed the decision to give the responsibility for second opinions to an independent consultant responsible to the Mental Health Act Commission, but many have expressed anxiety and concern about the extent of the requirement to obtain a second opinion, which appears to include virtually any medicine given to treat a patient's mental disorder, whether it be a commonly used hypnotic or a major tranquilliser. The same type of criticism applies to "diagnostic procedures." It is feared that the proposed arrangements may be so cumbersome and bureaucratic that some patients may fail to receive treatment they need while a second opinion is awaited. There has been uncertainty and speculation about the number of second opinions that might be required.

We report a study of the case notes of all detained patients admitted to two Birmingham psychiatric hospitals in 1981 to determine how often a second opinion would have been required if the proposed legislation had applied during that year.

\section{Method}

The two hospitals were All Saints' Hospital and Highcroft Hospital, Birmingham. Two-thirds of the inner city area of Birmingham lies within the catchment area of these two hospitals. All Saints' Hospital has 680 beds, is served by nine consultants, and the catchment area population is 415000 . Highcroft Hospital has 650 beds, seven consultants, and serves a catchment area population of 489000 .

Patients already in hospital detained on a compulsory order for treatment on 1 January 1981, and not on extended leave, were included in the study, together with all those placed on a compulsory detention section for treatment during 1981. Patients detained on a short-term section (sections 29,30,135, and 136) were excluded from analysis as a second opinion for their treatment would not have been necessary.

From the case notes the patients' diagnoses and the date on which the section was implemented were recorded.

For each patient, the number of decisions to initiate or change treatment during the detention period was noted-for example, prescribing a named drug such as chlorpromazine or thioridazine (not "a phenothiazine"), changing from one drug to another, adding another drug, and initiating electric convulsion therapy. The decision to start lithium therapy would include pre-lithium screening to estimate, for example, creatinine clearance and the taking of serial lithium estimations. This was all counted as one decision. A decision to prescribe more than one drug at one time was regarded as one decision.

Diagnostic procedures entailing a physical interference were recorded-for instance, venepuncture or lumbar puncture. In practice the decision to prescribe drugs was usually taken at the same time as the decision to take routine blood samples, usually at the time of admission, and this was counted as one decision.

Prescriptions of mild analgesics and laxatives, which were not given to treat a mental disorder, were excluded, as were drugs given to relieve a physical disorder, except where the physical disorder was adversely affecting the patient's mental state-for example, the prescription of antibiotics for lobar pneumonia in a patient with a toxic confusional state.

From a study of the case notes an assessment was made as to whether the patient was able to give informed consent. This is difficult to assess retrospectively. In general, if an acutely psychotic patient is detained in hospital for treatment it is unlikely that he or she would be able to give informed consent. Informed consent was deemed to have been given by such patients only if there was a clear statement to this effect in the notes.

Finally, the case notes were examined to determine whether a sustained diagnosis had been made at the time of admission. If this was the case it may be presumed that a treatment plan could have been made permitting the second opinion to cover several possible changes of treatment or diagnostic investigations (to monitor drug levels, for instance) or both.

\section{Results}

PATIENTS

The number of patients detained and the ratio of detained patients/ population served was broadly similar for the two hospitals studied, although more were admitted to All Saints' Hospital on short-term sections (table I). At Highcroft Hospital the consultants operate a

TABLE I-Admissions to the two hospitals in 1981

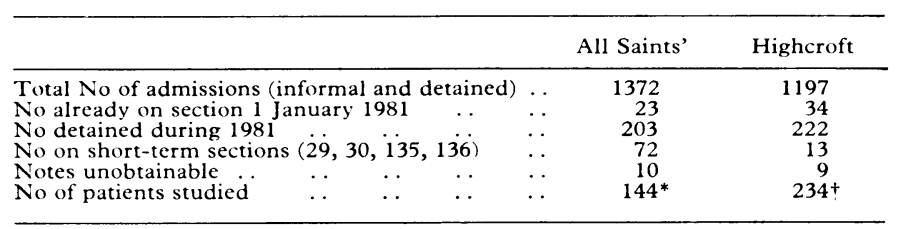

*Three patients were detained twice.

†Eleven patients were detained twice.

well-organised domiciliary service followed by admission of the patient, where necessary, on section 25 of the Act. Consequently, twice as many patients were detained at Highcroft under section 25 than was the case at All Saints' and fewer on section 29. It was evident, however, that most patients in both hospitals were transferred to informal status when the section 25 order expired. Those transferred to section 26 during the course of the year were recorded separately.

\section{CONSENT}

The recorded diagnosis for patients detained on treatment sections indicates that most suffered from acute psychoses (table II), and .

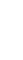
, 
most were considered to have been unable to give informed consent had the proposed procedures applied.

Twenty-four patients at All Saints and 33 at Highcroft were considered competent to consent to treatment (table III). Five patients from the two hospitals who were competent refused to accept treatment initially and either eventually accepted unwillingly or some compromise treatment plan was agreed with the patient after discussions. A further five patients were allowed to leave hospital on request.

TABLE II-Diagnosis of patients detained for treatment

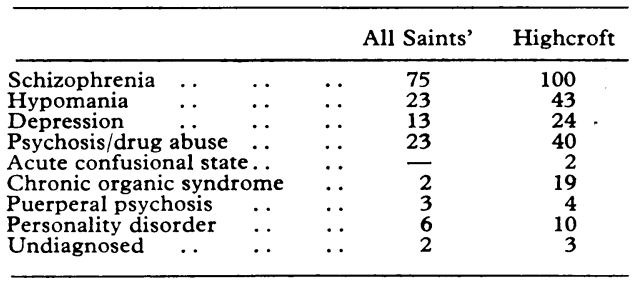

TABLE III-Competency and legal status

\begin{tabular}{|c|c|c|c|c|c|c|c|c|}
\hline Section & 25 & $\begin{array}{c}25 \\
\text { and } \\
26\end{array}$ & 26 & 60 & 65 & 72 & 73 & Total \\
\hline $\begin{array}{l}\text { Able to consent ... } \\
\text { Unable to consent }\end{array}$ & $\begin{array}{r}6 \\
88\end{array}$ & $\begin{array}{c}A l \\
2 \\
12\end{array}$ & $\begin{array}{c}\text { Saints' } \\
6 \\
10\end{array}$ & $\begin{array}{c}\text { ospital } \\
10 \\
10\end{array}$ & $\overline{1}$ & $\overline{2}$ & 二 & $\begin{array}{r}24 \\
123\end{array}$ \\
\hline Total .. & 94 & 14 & 16 & 20 & 1 & 2 & - & 147 \\
\hline $\begin{array}{l}\text { Able to consent .. } \\
\text { Unable to consent }\end{array}$ & $\begin{array}{r}21 \\
162\end{array}$ & $\begin{array}{c}1^{H} \\
18\end{array}$ & $\begin{array}{r}h c r o f t \\
8 \\
22\end{array}$ & $\begin{array}{c}\text { ospital } \\
3 \\
7\end{array}$ & $\overline{3}$ & $\overline{-}$ & Z & $\begin{array}{r}33 \\
212\end{array}$ \\
\hline Total . . & 183 & 19 & 30 & 10 & 3 & - & - & 245 \\
\hline
\end{tabular}

*Three patients were detained twice.

+Eleven patients were detained twice.

\section{TREATMENT DECISIONS}

For each patient the actual number of treatment or diagnostic decisions, each of which might require a second opinion, was recorded (table IV). In many cases a treatment programme incorporating several changes of treatment could have been predicted, reducing the number of treatment decisions requiring a second opinion to those necessary to initiate a new treatment plan.

The analysis showed that for 123 patients at All Saints' 264 individual treatment or diagnostic decisions were made. Further analysis indicated that treatment plans could have been made (where a diagnosis was established), and this would have resulted in 169 decisions requiring a second opinion for a treatment programme.

At Highcroft Hospital, 465 individual decisions were made for 212 patients. Treatment programmes would have reduced the number of decisions requiring a second opinion to 276 .

\section{TREATMENT AND DIAGNOSIS}

Table $\mathrm{V}$ shows the main categories of treatment given. All but one patient were treated with depot neuroleptics or non-depot neuroleptics

TABLE IV-Treatment decisions: detained patients unable to consent

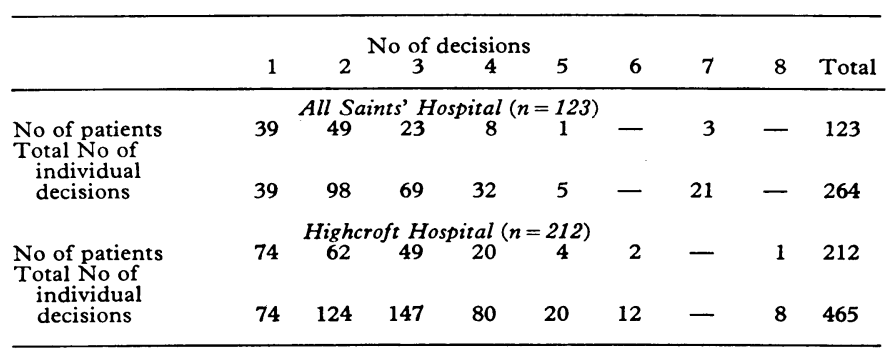

administered by mouth or intramuscularly. Some patients received more than one type of medication. All were subjected to venepuncture for routine and sometimes specific blood analysis. One patient had a lumbar puncture, one an enhanced examination by computed tomography, and one an intravenous infusion.

TABLE $\mathrm{v}-$ Treatment given: patient unable to consent

\begin{tabular}{lcccc}
\hline & & All Saints' & Highcroft \\
\hline Depot neuroleptics & $\ldots$ & $\ldots$ & 66 & 104 \\
Non-depot neuroleptics & $\ldots$ & 57 & 106 \\
Electric convulsion treatment.. & 25 & 46 \\
Lithium .. $\ldots$ & $\ldots$ & $\ldots$ & 6 & 19 \\
Antidepressants .. & $\ldots$ & $\ldots$ & 22 & 28 \\
& & & & \\
\hline
\end{tabular}

\section{Discussion}

The two hospitals in this study care for an inner city population, and the admission rate for patients detained on a treatment section of the Act was roughly twice the rate for England and Wales generally. All Saints' Hospital admitted 30 patients per 100000 and Highcroft Hospital 43 per 100000 . (England and Wales 17 per 100000 ). The admission rates for all patients (informal and detained) is slightly below the national average. The use of compulsory treatment orders is likely to be similar for other city psychiatric hospitals, but in rural areas and for many general hospital psychiatric units there will be fewer detained patients and the number of second opinions for treatment will be fewer. The situation for special hospitals which admit only detained patients will also differ. They do not admit patients on section 25 and have a low admission rate (191 admissions and 45 readmissions for the four special hospitals in 1979), but on 31 December 1979 they housed a total of 1995 detained patients- $25 \%$ of the resident population of compulsorily detained patients in all mental illness and mental handicap hospitals in England and Wales. This investigation attempts to predict some of the practical consequences of implementing clause 41 of the Mental Health (Amendment) Bill. We are not concerned here with the principles that underlie the proposals.

Our analysis of case notes indicates that at All Saints' Hospital 264 individual treatment or diagnostic decisions were made during 1981 in relation to 123 detained patients considered unable to give informed consent.

At Highcroft 465 individual treatment or diagnostic decisions were made for 212 patients unable to give informed consent. Assuming the availability of second opinions on a five-day week basis, this would mean a requirement of five second opinions each week at All Saints' Hospital and nine second opinions each week at Highcroft Hospital, an average of two second opinions per patient in each hospital a year (2.14 for All Saints': $2 \cdot 10$ for Highcroft).

If second opinions were provided to confirm a treatment programme, involving several predicted changes of drug or diagnostic procedures, then at All Saints' Hospital 169 second opinions would have been required for 123 patients and 276 second opinions for 212 patients at Highcroft. This would reduce the number of second opinions required to three per five-day week at All Saints' and five per five-day week at Highcroft (1.3 opinions per patient in All Saints' and 1.6 opinions per patient in Highcroft each year).

In England and Wales 8292 patients were detained on treatment sections in $1979 .{ }^{3}$ This investigation suggests that if a second opinion was required for each treatment or diagnostic decision, then 17413 second opinions would have been required for all patients detained on treatment sections in England and Wales in that year. If second opinions were required for treatment programmes (and some changes of plan) then 11608 second opinions would have been required in 1979. 
Our interpretation of the practice in the two hospitals, shown by retrospective analysis, may not reflect future practice. A second opinion may not be required for every patient on a section 25 order for instance. Subsection (6) of clause 41 permits treatment without a second opinion:

(a) which is immediately necessary to save the patient's life, or

(b) which (not being irreversible) is immediately necessary to prevent deterioration of his condition, or

(c) which (not being irreversible or hazardous) represents the minimum interference necessary to prevent the patient from behaving violently or being a danger to himself or to others.

Treatment of a patient on section 25 may, therefore, be started and the patient's ability to give informed consent himself (without the need for a second opinion) may improve. The need for a second opinion (or not) is, however, predominantly in relation to section 25 as may be seen from

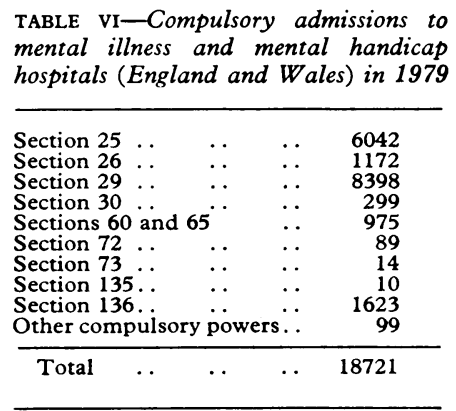

the statistics for England and Wales for 1979 (table VI). These figures include 191 patients admitted to the special hospitals.

It is also suggested that second opinions would mainly have to be found in large city NHS psychiatric hospitals which will ease their organisation. There are obvious manpower implications in providing this extra service to patients that wil particularly affect city hospitals (and possibly the special hospitals).

The patients included in this study are mentally ill, and the need for second opinions in mental handicap hospitals is not known.

This analysis suggests that there will be difficulties in operating the proposed arrangements. Although they may not be insurmountable, the Government should consider restricting the range of treatment and procedures for which a second opinion is a statutry requirement.

We acknowledge with thanks the co-operation of the consultants at All Saints' Hospital and Highcroft Hospital, Birmingham.

This paper was accepted in evidence by the Special Standing Committee of the House of Commons on the Mental Health (Amendment) Bill on 27 April 1982.

\section{References}

${ }^{1}$ Mental Health (Amendment) Bill. London: HMSO, 1981.

2 Mental Health Act 1959. London: HMSO, 1959.

${ }^{3}$ Department of Health and Social Security. Reform of Mental Health Legislation. Cmnd 8405. London: HMSO, 1981.

(Accepted 6 May 1982)

\title{
Lesson of the Week
}

\section{Delayed diagnosis of malaria}

\author{
G R WILLIAMS，T L LAW，D H KENNEDY，W C LOVE
}

In May and June 1981, 14 patients were admitted to the infectious diseases unit in Glasgow with malaria. We report on two patients in whom the diagnosis was delayed. Both had taken co-trimoxazole shortly before admission.

\section{Case reports}

Case 1-A 56-year-old construction engineer was admitted two weeks after returning from a 10-day stay in Madagascar. $\mathrm{He}$ had worked in the bush and had frequently been bitten by mosquitoes. For antimalarial prophylaxis he had taken only three tablets of unknown type given to him irregularly by a workmate. For three days he had been shivering and sweating and had increasing lassitude, headache, and cough. He had vomited twice and complained of dysuria and frequency. Co-trimoxazole

\footnotetext{
Departments of Infectious Diseases and Laboratory Medicine, Ruchill Hospital, Glasgow G20 9NB

G R WILLIAMS, MRCP, DTM\&H, lecturer

T L LAW, FIMLS, chief medical laboratory scientific officer

D H KENNEDY, MRCP, consultant physician

W C LOVE, FRCP, consultant physician
}

Treatment with co-trimoxazole may delay the diagnosis of malaria

at the standard dosage was started on the day before admission. On examination he was restless but not drowsy, his temperature was $38.5^{\circ} \mathrm{C}$, pulse 88 beats $/ \mathrm{min}$, and blood pressure $110 /$ $80 \mathrm{~mm} \mathrm{Hg}$. Coarse crepitations were heard at both lung bases, being more definite on the left. The edge of the liver was palpable $2 \mathrm{~cm}$ below the right costal margin but the spleen could not be felt. The marks of hundreds of insect bites were visible on his legs.

The results of initial haematological investigations were: haemoglobin $14.3 \mathrm{~g} / \mathrm{dl}$; white cell count $2.8 \times 10^{9} / 1\left(2800 / \mathrm{mm}^{3}\right)$ $\left(87 \%\right.$ neutrophils, $13 \%$ lymphocytes); platelets $25 \times 10^{9} / 1$ $\left(25 \mathrm{000} / \mathrm{mm}^{3}\right)$. No malarial parasites were seen on a thin blood film. No thick blood film was examined because investigations are restricted in patients who may have viral haemorrhagic fever. A chest $x$-ray examination showed bilateral inflammatory changes and pleural thickening on the left. (Asbestosis had been diagnosed 12 years earlier.)

Because there had been some clinical improvement in his condition before admission and enteric fever was a possible 